\title{
Z3 Research Square \\ Pathogenicity Reclassification of Genetic Variants Related to Early-Onset Breast Cancer among Buryat Women
}

\section{Polina Gervas ( $\sim$ gervaspa@oncology.tomsk.ru )}

Cancer Research Institute, Tomsk National Research Medical Center, Russian Academy of Science, Tomsk, Russia

\section{Aleksey Molokov}

Cancer Research Institute, Tomsk National Research Medical Center, Russian Academy of Science, Tomsk, Russia

\section{Artem Kiselev}

Federal Almazov North-West Medical Research Centre, St. Petersburg, Russia

\section{Aleksei Zarubin}

Research Institute of Medical Genetics, Tomsk National Research Medical Center, Russian Academy of Science, Tomsk, Russia

Evgeny Yumov

Buryat Republican Clinical Oncological Dispensary, Republic of Buryatia, Ulan-Ude, Russia

\section{Lubov Pisareva}

Cancer Research Institute, Tomsk National Research Medical Center, Russian Academy of Science, Tomsk, Russia

Evgeny Choynzonov Evgeny Choynzonov

Cancer Research Institute, Tomsk National Research Medical Center, Russian Academy of Science, Tomsk, Russia

Nadezda Cherdyntseva

Cancer Research Institute, Tomsk National Research Medical Center, Russian Academy of Science, Tomsk, Russia

\section{Research Article}

Keywords: germline mutation, breast cancer, small nationality of Russia, ethnic group, Buryat

Posted Date: September 1st, 2021

DOI: https://doi.org/10.21203/rs.3.rs-783155/v1

License: (c) (i) This work is licensed under a Creative Commons Attribution 4.0 International License. Read Full License 


\section{Abstract}

Background: Germline alterations in ATM, BRCA1, BRCA2, and other genes are responsible for early-onset breast cancer. However, up to $20 \%$ of molecular tests report genetic variant of unknown significance (VUS) or novel variants that have never been previously described and their clinical significance are unknown. An existing open access databases (ClinVar, BIC, and ENIGMA and other) play an important role in the interpretation of VUS, but in Asian populations the interpretation of VUS is still difficult due to restricted data. This study aimed to reclassify the genetic variants by using the ActiveDriveDB database that annotates variants through the lens of sites of post-translational modifications.

Methods: Our study included young Buryat BC patients, anthropologically belonging to the Central Asia. Genomic DNA was used to prepare libraries. NGS sequencing was performed on a NextSeq 500 System.

Results: We re-examined 135 rare variants (41 VUS, 25 conflicting, 64 benign and 5 new variants). We identified 10 out of 135 (7.4\%) mutations that affected the sites of post-translational modification in proteins. Of 135 rare mutations, 1 benign variant was reclassified as network-rewiring - motif loss mutation, 3 VUS and 1 new variant were reclassified as distal PTMmutations, 2 new and 1 benign variant were classified as proximal PTM- mutations and 1 benign and 1 conflicting variant were classified as direct PTM- mutations.

Conclusions: For the first time, 7.4\% (10 out of 135) of mutations that affected the sites of post-translational modification in proteins were identified among Buryat women with early-onset breast cancer.

\section{Introduction}

Breast cancer $(\mathrm{BC})$ is the most common female malignancy worldwide. Germline alterations in homologous recombination repair genes (ATM, APC, BARD1, BRCA1, BRCA2, BRIP1, CDH1, CHEK2 and other) are responsible for early-onset BC or ovarian cancer incidence in 7-15\% patients among different ethnic groups. Individuals with clinically significant inherited mutations should be offered the risk-reduction strategies, surveillance and chemoprevention [1].

Currently, the molecular diagnosis of hereditary breast and ovarian cancers has become more available with the use of nextgeneration sequencing. Next generation sequencing allows detecting DNA damage of five levels of pathogenicity (not pathogenic, likely not pathogenic, uncertain, likely pathogenic, pathogenic). However, up to $20 \%$ of molecular tests report genetic variant of unknown significance (VUS) or novel variants that have never been previously described and their clinical significance are unknown. The interpretation of VUS is still a major challenge for specialists involved in NGS data analysis and therapy administration. Misinterpretation of VUS can lead to serious clinical mistakes for patients and their families. In accordance to literature data, Asians and African-Americans have higher rates of VUS then well-characterized Caucasians [2]. An existing open access databases (ClinVar, BIC, and ENIGMA and other) play an important role in the interpretation of VUS, but in Asian populations the interpretation of VUS is still difficult due to restricted data.

Breast cancer related gene aberrations are known to be various in different ethnic groups. There are limited data on hereditary BC associated mutations in Buryat BC patients (small nationality of Russia, up to $0,5 \%$ ). Republic of Buryatia is a federal subject of Russia located in Central Asia or in the south of Eastern Siberia. Our previous study has been aimed to identify the BC-associated genes in 38 Buryats BC patients living in Siberia (Russian Federation). The pathogenic variants in two non-BRCA1/2 susceptibility genes, such as RAD51D (rs137886232) and PTEN (rs786201044) were found only in three $\mathrm{BC}$ patients aged under 45 years old [3]. Thus, $8 \%$ (3/39) of patients harbored one pathogenic variant and $92 \%$ of patients with early-onset BC had rare VUS, conflicting and benign variants. Thus, there is a growing need for scientifically rigorous additional approaches for extended annotation of rare variants.

This study aimed to reclassify the variants of unknown significance and others (benign/likely benign variants, variants with conflicting interpretations of pathogenicity and novel variants) using the comprehensive human proteo-genomics ActiveDriveDB database. The open-source database is available at https://www.ActiveDriverDB.org. The human proteo- 
genomics ActiveDriveDB database contains more than 385,000 mutations associated with post-translational modification sites (PTM mutations) and numerous amino acid substitutions from The Cancer Genome Atlas, ClinVar and other projects. This program simulates site-specific interaction networks of proteins with upstream enzymes and approved drugs [4].

\section{Materials And Methods}

Thirty- eighth patients were included into the study. The median age of patients at BC diagnosis was 42 years (range: 2655). Eighty-one percent of patients were diagnosed with $\mathrm{BC}$ before the age of 50 . More than one-third of patients under the age of 50 had a family history of BC.

Blood was collected in blood tubes containing K2EDTA. Genomic DNA was extracted from the peripheral blood lymphocytes using the phenol/chloroform method. Purity of the DNA was determined by NanoDrop 1000 spectrophotometer (Thermo Fisher Scientific, USA) and then quantified by Qubit 2.0 fluorometer and HS dsDNA Assay Kit (Thermo Fisher Scientific, USA). Integrity of the DNA (DIN) was verified on a 2200 TapeStation system (Agilent, USA). DNA library were prepared using the Hereditary Cancer Solution ${ }^{\text {TM }}$ kit (Sophia GENETICS, Switzerland) to cover 27 genes, such as ATM, APC, BARD1, BRCA1, BRCA2, BRIP1, CDH1, CHEK2, EPCAM, FAM175A, MLH1, MRE11A, MSH2, MSH6, MUTYH, NBN, PALB2, PIK3CA, PMS2, PMS2CL, PTEN, RAD50, RAD51C, RAD51D, STK11, TP53, and XRCC2. Paired-end sequencing (2 x 150 bp) was conducted using NextSeq 500 system (Illumina, USA).

\section{Bioinformatics Analysis}

Sequencing data was analyzed according to the GATK (Genome Analysis Toolkit) best practice recommendation for Whole Exome Sequencing using GRCh37 as a reference for Burrows-Wheeler alignment. The obtained variants were annotated with ANNOVAR software and ranged according to population frequency (genomic exome, gnomAD genome, and ExAC), ClinVar, CADD, and literature data $[5,6,7]$. Detected sequence variants were annotated using PolyPhen2, Mutation Taster, and SIFT [8, $9,10]$.

The open-source database is available at https://www.ActiveDriverDB.org (Ontario Institute for Cancer Research). The VCF files were aligned to hg19/GRCh37 version of the human genome. NGS data were further annotated regarding their position in post-translational modifications sites. Depending on the location of amino acid substitutions in the post-translational modification sites, mutations can be described as direct (central amino acid residue of the PTM site) or indirect (proximal or distal if they replace 1-2 or 3-7 amino acid residues from the nearest PTM site, respectively). An assessment of the network impact of mutations also was carried out using ActiveDriverDB.

\section{Results}

There are limited data on hereditary BC associated mutations in Buryat BC patients. Our previous study aimed to identify the BC-associated genes in 38 Buryats BC patients by NGS. They were previously assessed as negative for BRCA1/2 mutation (BRCA1 5382insC, BRCA1 185delAG, BRCA1 4153delAG, BRCA1 T300G, BRCA2 6174delT) which consider as pathogenic in Slavic population. This study included 38 women with at least one clinical sign of hereditary breast cancer. In $92 \%$ of patients with early onset BC, VUS and conflicting or benign variants that complicated clinical diagnosis were found.

In this study we re-examined 135 rare variants, including 41 variants reported to be VUS, 26 conflicting variants, 64 benign/likely benign variants, and 5 new variants. We identified 10 out of 135 (7.4\%) mutations that affected the sites of post-translational modification in proteins. Rare genetic variants classified by ActiveDriverDB as PTM-associated mutations are given in Table 1 and Fig. 1. 
Table 1

Rare genetic variants classified by ActiveDriverDB as PTM-associated mutations

\begin{tabular}{|c|c|c|c|c|c|c|c|}
\hline $\begin{array}{l}\text { CLNSIG } \\
\text { dbPubMed }\end{array}$ & Gene & dbSNP ID & $\begin{array}{l}\text { Chr: } \\
\text { position:substitution } \\
\text { (MAF) }\end{array}$ & $\begin{array}{l}\text { SIFT } \\
\text { /PolyPen2 }\end{array}$ & $\begin{array}{l}\text { PTM- } \\
\text { associated } \\
\text { mutations } \\
\text { localization }\end{array}$ & $\begin{array}{l}\text { BC } \\
\text { patients } \\
\text { age }\end{array}$ & $\begin{array}{l}\text { Family } \\
\text { history }\end{array}$ \\
\hline \multirow[t]{6}{*}{$\begin{array}{l}\text { Benign } \\
\text { /Likely } \\
\text { benign }\end{array}$} & BRCA2 & rs28897727 & $\begin{array}{l}\text { 13:32912750:G > T } \\
T=0.006497 \\
\text { (GnomAD_exome) }\end{array}$ & $\begin{array}{l}\text { tolerated/ } \\
\text { probably } \\
\text { damaging }\end{array}$ & Proximal & 36 & $\begin{array}{l}\text { Grandmother } \\
\text { - stomach } \\
\text { cancer }\end{array}$ \\
\hline & \multirow[t]{4}{*}{ EPCAM } & \multirow[t]{4}{*}{ rs74531854 } & \multirow{4}{*}{$\begin{array}{l}\text { 2:47604176:C > T ,T } \\
=0.005685 \\
\text { (GnomAD_exome) }\end{array}$} & \multirow{4}{*}{$\begin{array}{l}\text { deleterious/ } \\
\text { benign }\end{array}$} & \multirow[t]{4}{*}{ Direct } & 48 & No data \\
\hline & & & & & & 54 & $\begin{array}{l}\text { Sister - } \\
\text { breast } \\
\text { cancer }\end{array}$ \\
\hline & & & & & & 55 & $\begin{array}{l}\text { Sister - } \\
\text { adrenal } \\
\text { cancer }\end{array}$ \\
\hline & & & & & & 36 & $\begin{array}{l}\text { Grandmother } \\
\text { - stomach } \\
\text { cancer }\end{array}$ \\
\hline & NBN & rs192236678 & $\begin{array}{l}\text { 8:90965508:G > T T } \\
=0.0003 \\
\text { (GnomAD_exome) }\end{array}$ & $\begin{array}{l}\text { tolerated/ } \\
\text { benign }\end{array}$ & $\begin{array}{l}\text { Network- } \\
\text { rewiring - } \\
\text { motif loss }\end{array}$ & 40 & $\begin{array}{l}\text { No burdened } \\
\text { family } \\
\text { history }\end{array}$ \\
\hline \multirow[t]{4}{*}{ VUS } & \multirow[t]{2}{*}{ MLH1 } & \multirow[t]{2}{*}{ rs4986984 } & \multirow[t]{2}{*}{$\begin{array}{l}\text { 3:37053562: } \mathrm{C}>\mathrm{T} \mathrm{T} \\
=0.0003 \text { (ExAC) }\end{array}$} & \multirow[t]{2}{*}{$\begin{array}{l}\text { deleterious/ } \\
\text { probably } \\
\text { damaging }\end{array}$} & \multirow[t]{2}{*}{ Distal } & 46 & $\begin{array}{l}\text { No burdened } \\
\text { family } \\
\text { history }\end{array}$ \\
\hline & & & & & & 26 & $\begin{array}{l}\text { No burdened } \\
\text { family } \\
\text { history }\end{array}$ \\
\hline & MSH6 & rs61756469 & $\begin{array}{l}2: 48010479: \mathrm{C}>\mathrm{T} \mathrm{T} \\
=0.0001(\text { ExAC) }\end{array}$ & $\begin{array}{l}\text { Tolerated } \\
\text { low } \\
\text { confidence/ } \\
\text { benign }\end{array}$ & Distal & 32 & $\begin{array}{l}\text { No burdened } \\
\text { family } \\
\text { history }\end{array}$ \\
\hline & BRCA2 & rs80359254 & $\begin{array}{l}13: 32972584: A>G \\
G=0.0000(\text { ExAC) }\end{array}$ & $\begin{array}{l}\text { tolerated/ } \\
\text { benign }\end{array}$ & Distal & 49 & $\begin{array}{l}\text { No burdened } \\
\text { family } \\
\text { history }\end{array}$ \\
\hline Conflicting & ATM & rs150757822 & $\begin{array}{l}11: 108183194: A>C \\
C=0.0003(\text { ExAC) }\end{array}$ & $\begin{array}{l}\text { tolerated/ } \\
\text { benign }\end{array}$ & Direct & 49 & $\begin{array}{l}\text { Sister - } \\
\text { cervical } \\
\text { cancer }\end{array}$ \\
\hline \multirow[t]{3}{*}{$\begin{array}{l}\text { New } \\
\text { mutation }\end{array}$} & APC & - & $5: 112178383: G>A$ & - & Distal & 55 & $\begin{array}{l}\text { Sister - } \\
\text { adrenal } \\
\text { cancer }\end{array}$ \\
\hline & BRCA1 & - & 17:41244039:A > G & - & Proximal & 45 & No data \\
\hline & MSH2 & - & $2: 47705411: G>C$ & - & Proximal & 47 & No data \\
\hline
\end{tabular}

Distal PTM-associated mutations of MLH1 gene (rs4986984) were found in two young BC patients with no burdened family history. Direct PTM-associated mutations of EPCAM gene (rs74531854) were found in three BC patients with burdened family history and in one young patient with no burdened family history. Another network-rewiring - motif loss mutations of NBN gene (rs192236678) were found in a 40-year-old patient with no burdened family history (Fig. 2).

Proximal PTM-associated mutations of BRCA1 gene (17:41244039:A > G) were found in a 45-year-old BC patient. ActiveDriverDB analysis suggests that 17:41244039:A > G substitution of BRCA1 gene may induce gains of phosphosites of 
the PLK1 kinase that pharmaceutically targetable by Fostamatinib (Fig. 3).

\section{Discussion}

Our previous study was aimed to identify the BC-associated genes in 38 Buryats BC patients. The pathogenic variants in two non-BRCA1/2 susceptibility genes, such as RAD51D (rs137886232) and PTEN (rs786201044) were found in three BC patients aged under 45 years old [3]. Thus, $8 \%(3 / 38)$ of patients harbored pathogenic variant. In $92 \%$ of patients with early onset BC, VUS and conflicting or benign variants that complicated clinical diagnosis were found. All obtained variants were annotated with ANNOVAR software and ranged according to the population frequency, clinical significance and impact on protein function (gnomAD genome, ExAC, ClinVar, CADD, PolyPhen2, Mutation Taster, and SIFT) and literature data.

Variants of uncertain significance (VUS) or unclassified variants (UVs) are rare missense substitutions, including in-frame deletions or insertions, silent coding alterations, intronic changes. Variants of uncertain significance have unknown functional effects on proteins and cannot be classified as either «Pathogenic» or «Not Pathogenic». The frequency of VUS for BRCA $1 / 2$ genes accounts for $30 \%-50 \%$ in many countries. In the USA, these variants account for $5 \%-10 \%$ due to ongoing classification efforts [11]. The interpretation of VUS is a major challenge for specialists involved in NGS data analysis and therapy administration. For example, open-access databases and research consortia (ClinVar, the BIC, ENIGMA and other) playing an important role for the interpretation of VUS for patients from Western countries are not suitable for variants found in Asian or other ethnic populations [2]. Moreover, the authors suggest that caution should be exercised when analyzing data of Asian populations (Chinese, Japanese, Koreans). For example, the use of ExAC EAS (East Asian), which is mainly composed of Chinese and Japanese, led to misleadingly in assessing the frequency of variants found among Koreans. It became apparent when an extended own control group consisting of Korean population was used. Tsai et al. (2019) reported that family studies are an important source for classification of rare VUS in the general population. There is a FindMyVariant.org website designed to educate and assist individuals in pursuing family studies for VUS reclassification. At the same time, the authors note that VUS reclassification through family studies has a number of limitations (communicating with families, collecting family history for building pedigrees, interest and awareness of patients). Pål Møller et al. reported that family history detected less than $50 \%$ of the mutation carriers [13].

In our study, along with the well-known ClinVar, PolyPhen2, Mutation Taster, and SIFT databases we used the open-source database https://www.ActiveDriverDB.org (Ontario Institute for Cancer Research), which annotates mutations through the prism of post-translational modification sites (PTMs). After translation, proteins undergo different post-translational modifications (PTMs) or chemical modifications (phosphorylation, glycosylation, ubiquitination, SUMOylation, acetylation, and lipidation) that impact their activity and function. PTMs influence many processes in the cell, including protein activation and degradation, protein-protein interactions, chromatin organization, development, and signaling pathways associated with different types of cancers [14]. Mutations at PTM sites could alter sequence motifs linked by PTM enzymes and can affect signaling networks. Further, PTMs provide potential sites of intervention and could be used in precision cancer therapies. Krassowski et al. (2018) reported that up to $30 \%$ of mutations in PTM sites were considered «benign» by tools such as PolyPhen2, SIFT and others. ActiveDriverDB were designed as proteo-genomics resource to find mutations located in the human PTM sites mutations, to display the network context, to visualize protein-protein interactions and to apply the drugs targeting PTM enzymes.

Network-rewiring - motif loss mutations of NBN gene. Nibrin, encoded by the NBN gene recognize the DNA double-strand breaks during the non-homologous end- joining (NHEJ) and induce cell-cycle checkpoint to provide genomic stability. Mutations in the NBN gene lead to Nijemen breakage syndrome, which may result in particularly susceptibility to cancer, including breast cancer [15]. In our study, network-rewiring - motif loss mutations of NBN gene (rs192236678) were found in a 40-year-old BC patient with no burdened family history. The rs 192236678 mutation of NBN gene is predicted to disrupt the sequence motif and change the identity of these residues and specificity the PDPK1 kinase. It is well known that 3-

phosphoinositide dependent protein kinase 1 (PDPK1 kinase) is the first goal in the PI3K/AKT/mTOR pathway signaling. The oncogenic potential of aberrant PI3K pathway signaling through PDK1 to AKT has been well demonstrated [16]. Given that

Page 5/12 
the significance of the affected phosphorylation sites is well known, these network-rewiring - motif loss mutations of NBN gene could be considered as candidates for further studies.

New PTM-associated mutations of BRCA1 gene associated with drugs targeting kinase. BRCA1 plays a crucial role in DNA repair, cell cycle control and genomic stability [17]. Germline BRCA1 mutations are the main hallmark for hereditary breast and ovarian cancers. Proximal PTM-associated mutations of BRCA1 gene (17:41244039:A > G) were found in a 45-year-old $B C$ patient. ActiveDriverDB analysis suggests that 17:41244039:A > G substitution of BRCA1 gene may induce gains of phosphosites of the PLK1 kinase that is pharmaceutically targeted by Fostamatinib. PLK1 kinase is a critical regulator of the cell cycle and an inhibitor of apoptosis. PLK1 kinase overexpression in various tumors has been associated with poor prognosis. Although a number of small molecule inhibitors of PLK1 have been studied as anticancer agents [18]. Shinde et al. (2019) in vivo data suggest that Fostamatinib could be considered as an effective treatment option for the prevention of metastatic recurrence in breast cancer.

Rare variant of EPCAM gene impacting the phosphorylation site. Epithelial cell adhesion molecule (EpCAM) is a transmembrane glycoprotein mediating Ca2+-independent homotypic cell-cell adhesion in epithelia. EpCAM is involved in cell signaling, migration, proliferation, and differentiation. Deletions in EPCAM gene are associated with Lynch hereditary cancer syndrome leading to different types of cancer [20]. Direct PTM-associated rare mutations of EPCAM gene (rs74531854, 2:47604176:C > T, T = 0.005685 (GnomAD_exome)) were found in three BC patients with burdened family history and in one young patient with no burdened family history. The significance of the rs74531854 of the EPCAM gene may be revised in the future, taking into account its frequency, location in the center of the phosphorylation site, as well as the fact of its detection in three BC patients with a family history.

In our study, over $30 \%$ of the Buryat BC patients were found to carry a VUS. In accordance with DM Eccles, 2015, the frequency of the VUS can reach $20 \%$ in poorly studied populations and drop to $5 \%$ percent for well-studied populations [21]. Our study included 38 Buryat BC patients, anthropologically belonging to the Central Asia. Republic of Buryatia is a federal subject of Russia located in Central Asia or in the south of Eastern Siberia [22]. Buryats are characterized by molecular diversity due to the long generation time or the mixed nature of origin compared with other ethnic groups living in Siberia [23, $24,25,26]$. It is obvious that a more detailed genetic analysis of the Buryats is required.

Due to the fact that the territory of Eastern Siberia remains unaffected by large-scale studies, mutations in BRCA1/2 genes associated with BC have not yet been found in Buryats. However, the cancer burden in Buryats has risen and the cancer risk assessment has been limited [27]. Modern approaches of molecular oncology have a sufficient depth to solve issues of early diagnosis of hereditary BC in ethnic groups. ActiveDriverDB is a great alternative approach for annotation of genetic variants found in Buryats population. The ability to assess the effects of specific genetic variants in a biological context makes ActiveDriverDB uniquely informative for reclassification of VUS and other findings.

\section{Conclusion}

NGS is an appropriate tool to detect hereditary mutation associated with BC or ovarian cancer. The detection of new pathogenic mutations is a great possibility to diagnose cancer on early stage or to prevent cancer development. However, up to $20 \%$ of molecular tests report genetic variant of unknown significance (VUS) or novel variants that have never been previously described and their clinical significance are unknown. This study was aimed to reclassify the variants of unknown significance and others (benign/likely benign variants, variants with conflicting interpretations of pathogenicity and novel variants) using the comprehensive human proteo-genomics ActiveDriveDB database.

In our study, out of 135 rare mutations, 10 were reclassified as PTM-associated mutations (7.4\%). Given the fact that the population of Buryats is poorly studied, the data obtained using ActiveDriverDB cannot be neglected. We reclassified not only rare VUS and benign mutations, but also newly found mutations. It is obvious that a more detailed genetic analysis of our findings in Buryat population is required to identify pathogenic mutations and for effective patient monitoring.

Page 6/12 


\section{Declarations}

\section{Ethical Approval and Consent to Participate}

The study was approved by the Ethics Committee of the Cancer Research Institute (Tomsk National Research Medical Center, Russian Academy of Science, Tomsk, Russia) in accordance with the Helsinki Declaration, printed in the British Medical Journal (18 July 1964). All patients were informed about the study and provided written informed consent.

\section{Consent for publication}

Not Applicable

\section{Availability of data and material}

The data that support the findings of this study are available from the corresponding author upon reasonable request.

\section{Competing Interest}

All authors declare no competing interests.

\section{Funding}

The reported study was funded by RFBR according to research project 18-29-09046.

\section{Authors' contributions}

PG, AM, EY recruited patients, collected samples and conducted experiments. AK and AZ performed data analysis. PG wrote the manuscript; and revised the manuscript. EC, NC and LPsupervised the project. All authors reviewed and approved the manuscript.

\section{Acknowledgements}

We acknowledge the Tomsk State University for the Competitiveness Improvement Program. The work with DNA sequencing was performed on equipment from the Tomsk regional common use center with the support of the Russian Ministry; Agreement No.14.594.21.0001 (RFMEFI59414X0001).

\section{References}

1. Dutil, J., Teer, J. K., Golubeva, V., Yoder, S., Tong, W. L., Arroyo, N., Karam, R., Echenique, M., Matta, J. L., \& Monteiro, A. N. (2019). Germline variants in cancer genes in high-risk non-BRCA patients from Puerto Rico. Scientific reports, 9(1), 17769. https://doi.org/10.1038/s41598-019-54170-6

2. Park, J. S., Nam, E. J., Park, H. S., Han, J. W., Lee, J. Y., Kim, J., Kim, T. I., \& Lee, S. T. (2017). Identification of a Novel BRCA1 Pathogenic Mutation in Korean Patients Following Reclassification of BRCA1 and BRCA2 Variants According to the ACMG Standards and Guidelines Using Relevant Ethnic Controls. Cancer research and treatment, 49(4), 1012-1021. https://doi.org/10.4143/crt.2016.433

3. Gervas, P., Molokov, A., Schegoleva, A., Kiselev, A., Babyshkina, N., Pisareva, L., Tyukalov, Y., Choynzonov, E., \& Cherdyntseva, N. (2020). New germline mutations in non-BRCA genes among breast cancer women of Mongoloid origin. Molecular biology reports, 47(7), 5315-5321. https://doi.org/10.1007/s11033-020-05612-2

4. Krassowski, M., Paczkowska, M., Cullion, K., Huang, T., Dzneladze, I., Ouellette, B., Yamada, J. T., Fradet-Turcotte, A., \& Reimand, J. (2018). ActiveDriverDB: human disease mutations and genome variation in post-translational modification sites of proteins. Nucleic acids research, 46(D1), D901-D910. https://doi.org/10.1093/nar/gkx973 
5. Van der Auwera, G. A., Carneiro, M. O., Hartl, C., Poplin, R., Del Angel, G., Levy-Moonshine, A., Jordan, T., Shakir, K., Roazen, D., Thibault, J., Banks, E., Garimella, K. V., Altshuler, D., Gabriel, S., \& DePristo, M. A. (2013). From FastQ data to high confidence variant calls: the Genome Analysis Toolkit best practices pipeline. Current protocols in bioinformatics, 43(1110), 11.10.1-11.10.33. https://doi.org/10.1002/0471250953.bi1110s43

6. DePristo, M. A., Banks, E., Poplin, R., Garimella, K. V., Maguire, J. R., Hartl, C., Philippakis, A. A., del Angel, G., Rivas, M. A., Hanna, M., McKenna, A., Fennell, T. J., Kernytsky, A. M., Sivachenko, A. Y., Cibulskis, K., Gabriel, S. B., Altshuler, D., \& Daly, M. J. (2011). A framework for variation discovery and genotyping using next-generation DNA sequencing data. Nature genetics, 43(5), 491-498. https://doi.org/10.1038/ng.806

7. McKenna, A., Hanna, M., Banks, E., Sivachenko, A., Cibulskis, K., Kernytsky, A., Garimella, K., Altshuler, D., Gabriel, S., Daly, M., \& DePristo, M. A. (2010). The Genome Analysis Toolkit: a MapReduce framework for analyzing next-generation DNA sequencing data. Genome research, 20(9), 1297-1303. https://doi.org/10.1101/gr.107524.110

8. Adzhubei, I. A., Schmidt, S., Peshkin, L., Ramensky, V. E., Gerasimova, A., Bork, P., Kondrashov, A. S., \& Sunyaev, S. R. (2010). A method and server for predicting damaging missense mutations. Nature methods, 7(4), 248-249. https://doi.org/10.1038/nmeth0410-248

9. Schwarz, J. M., Cooper, D. N., Schuelke, M., \& Seelow, D. (2014). MutationTaster2: mutation prediction for the deepsequencing age. Nature methods, 11(4), 361-362. https://doi.org/10.1038/nmeth.2890

10. Kumar, P., Henikoff, S., \& Ng, P. C. (2009). Predicting the effects of coding non-synonymous variants on protein function using the SIFT algorithm. Nature protocols, 4(7), 1073-1081. https://doi.org/10.1038/nprot.2009.86

11. Hofstra, R. M., Spurdle, A. B., Eccles, D., Foulkes, W. D., de Wind, N., Hoogerbrugge, N., Hogervorst, F. B., \& IARC Unclassified Genetic Variants Working Group (2008). Tumor characteristics as an analytic tool for classifying genetic variants of uncertain clinical significance. Human mutation, 29(11), 1292-1303. https://doi.org/10.1002/humu.20894

12. Tsai, G. J., Rañola, J., Smith, C., Garrett, L. T., Bergquist, T., Casadei, S., Bowen, D. J., \& Shirts, B. H. (2019). Outcomes of 92 patient-driven family studies for reclassification of variants of uncertain significance. Genetics in medicine : official journal of the American College of Medical Genetics, 21(6), 1435-1442. https://doi.org/10.1038/s41436-018-0335-7

13. Møller, P., Hagen, A. I., Apold, J., Maehle, L., Clark, N., Fiane, B., Løvslett, K., Hovig, E., \& Vabø, A. (2007). Genetic epidemiology of BRCA mutations-family history detects less than $50 \%$ of the mutation carriers. European journal of cancer (Oxford, England : 1990), 43(11), 1713-1717. https://doi.org/10.1016/j.ejca.2007.04.023

14. Samaržija I. (2021). Post-Translational Modifications That Drive Prostate Cancer Progression. Biomolecules, $11(2), 247$. https://doi.org/10.3390/biom11020247

15. Uzunoglu, H., Korak, T., Ergul, E., Uren, N., Sazci, A., Utkan, N. Z., Kargi, E., Triyaki, Ç., \& Yirmibesoglu, O. (2016). Association of the nibrin gene (NBN) variants with breast cancer. Biomedical reports, 4(3), 369-373. https://doi.org/10.3892/br.2016.579

16. Maurer, M., Su, T., Saal, L. H., Koujak, S., Hopkins, B. D., Barkley, C. R., Wu, J., Nandula, S., Dutta, B., Xie, Y., Chin, Y. R., Kim, D. I., Ferris, J. S., Gruvberger-Saal, S. K., Laakso, M., Wang, X., Memeo, L., Rojtman, A., Matos, T., Yu, J. S., ... Parsons, R. (2009). 3-Phosphoinositide-dependent kinase 1 potentiates upstream lesions on the phosphatidylinositol 3-kinase pathway in breast carcinoma. Cancer research, 69(15), 6299-6306. https://doi.org/10.1158/0008-5472.CAN-09-0820

17. Wang, B., Hurov, K., Hofmann, K., \& Elledge, S. J. (2009). NBA1, a new player in the Brca1 A complex, is required for DNA damage resistance and checkpoint control. Genes \& development, 23(6), 729-739.

https://doi.org/10.1101/gad.1770309

18. Abramson H. N. (2016). Kinase inhibitors as potential agents in the treatment of multiple myeloma. Oncotarget, 7(49), 81926-81968. https://doi.org/10.18632/oncotarget.10745

19. Shinde, A., Hardy, S. D., Kim, D., Akhand, S. S., Jolly, M. K., Wang, W. H., Anderson, J. C., Khodadadi, R. B., Brown, W. S., George, J. T., Liu, S., Wan, J., Levine, H., Willey, C. D., Krusemark, C. J., Geahlen, R. L., \& Wendt, M. K. (2019). Spleen Tyrosine Kinase-Mediated Autophagy Is Required for Epithelial-Mesenchymal Plasticity and Metastasis in Breast Cancer. Cancer research, 79(8), 1831-1843. https://doi.org/10.1158/0008-5472.CAN-18-2636

Page $8 / 12$ 
20. Morris, B., Hughes, E., Rosenthal, E., Gutin, A., \& Bowles, K. R. (2016). Classification of genetic variants in genes associated with Lynch syndrome using a clinical history weighting algorithm. BMC genetics, 17(1), 99.

https://doi.org/10.1186/s12863-016-0407-0

21. Eccles, D. M., Mitchell, G., Monteiro, A. N., Schmutzler, R., Couch, F. J., Spurdle, A. B., Gómez-García, E. B., \& ENIGMA Clinical Working Group (2015). BRCA1 and BRCA2 genetic testing-pitfalls and recommendations for managing variants of uncertain clinical significance. Annals of oncology: official journal of the European Society for Medical Oncology, 26(10), 2057-2065. https://doi.org/10.1093/annonc/mdv278

22. Cherdyntseva, N., Gervas, P., Voropaeva, E., Denisov, E., Pisareva, L., Malinovskaya, E., Maksimov, V., Voevoda, M., Perinov, D., Panferova, Y., Cherdyntsev, E., \& Choynzonov, E. (2017). New variants in the BRCA1 gene in Buryat Mongol breast cancer patients: Report from two families. Cancer biomarkers: section A of Disease markers, 18(3), 291-296. https://doi.org/10.3233/CBM-161649

23. Stepanov, V. A., Spiridonova, M. G., \& Puzyrev, V. P. (2003). Comparative phylogenetic study of native north Eurasian populations from a panel of autosomal microsatellite loci. Genetika, 39(11), 1564-1572.

24. Stepanov, V. A., Spiridonova, M. G., Tadinova, V. N., \& Puzyrev, V. P. (2003). Analysis of genetic diversity of population of Northern Eurasia from autosomal microsatellite loci. Genetika, 39(10), 1381-1388.

25. Har'kov, V. N., Hamina, K. V., Medvedeva, O. F., Simonova, K. V., Eremina, E. R., \& Stepanov, V. A. (2014). Gene pool of Buryats: clinal variability and territorial subdivision based on data of Y-chromosome markers. Genetika, 50(2), 203-213.

26. Khitrinskaia, I., Khar'kov, V. N., \& Stepanov, V. A. (2010). Genetic diversity of X-chromosome in populations of aboriginal Siberian ethnic groups: linkage disequilibrium structure and haplotype philogeography of ZFX locus. Mol Biol,44(5), 804-815.

27. Cherdyntseva, N. V., Pisareva, L. F., Ivanova, A. A., Panferova, Y. V., Malinovskaya, E. A., Odintsova, I. N., Doroshenko, A. V., Gervas, P. A., Slonimskaya, E. M., Shivit-ool, A. A., Dvornichenko, V. V., \& Choinzonov, Y. L. (2014). Ethnic aspects of hereditary breast cancer in the region of Siberia. Vestnik Rossiiskoi akademii meditsinskikh nauk, (11-12), 72-79. https://doi.org/10.15690/vramn.v69i11-12.1186

\section{Figures}



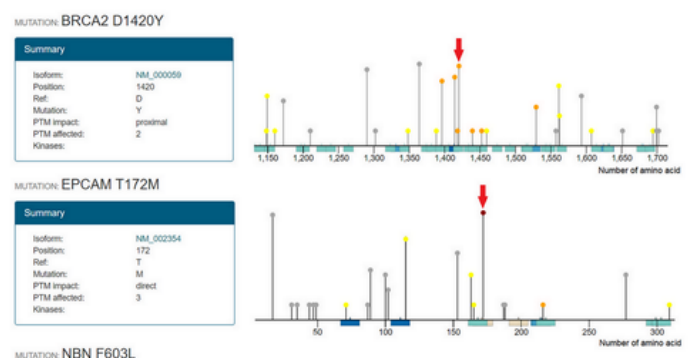

wroton NBN F603L
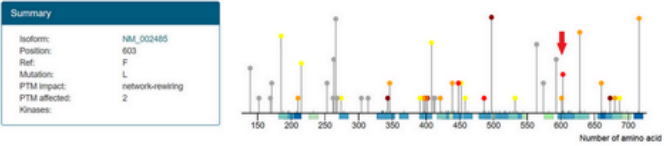

wewroc MLH1 R217C
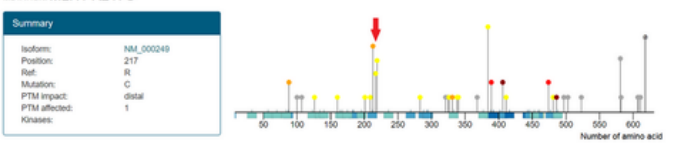

wTATOK MSH6 A36V
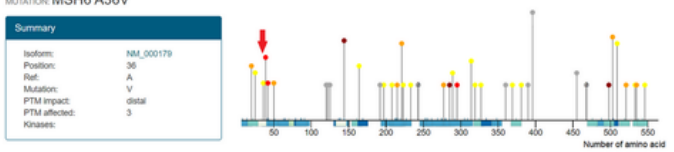

MUThON BRCA2 $13312 \mathrm{~V}$
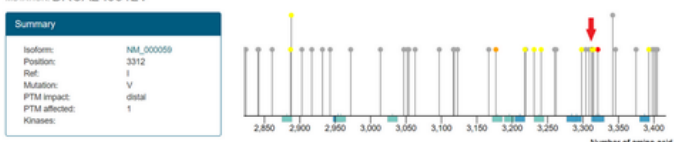

wuranoe ATM K1992T
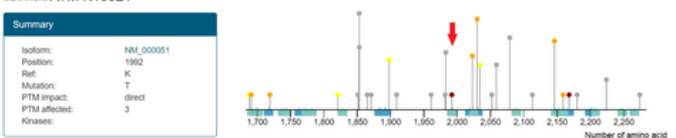

$$
\text { waranot BRCA1 11123T }
$$
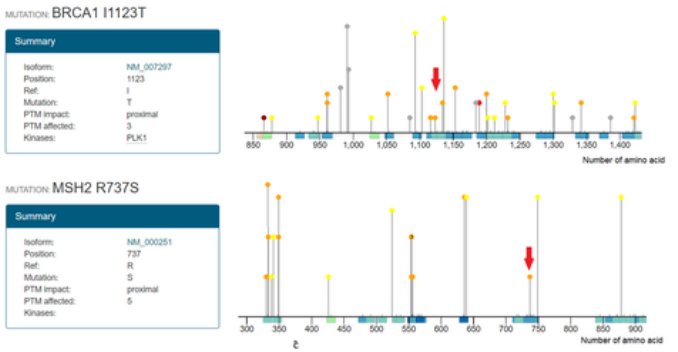

\section{Figure 1}

a. Zoomed needle plot shows location PTM-associated mutations of the BRCA2, EPCAM, NBN genes. b. Zoomed needle plot shows location PTM-associated mutations of the MLH1, MSH6, BRCA2 genes. c. Zoomed needle plot shows location PTMassociated mutations of the ATM, BRCA1, MSH2 genes. 


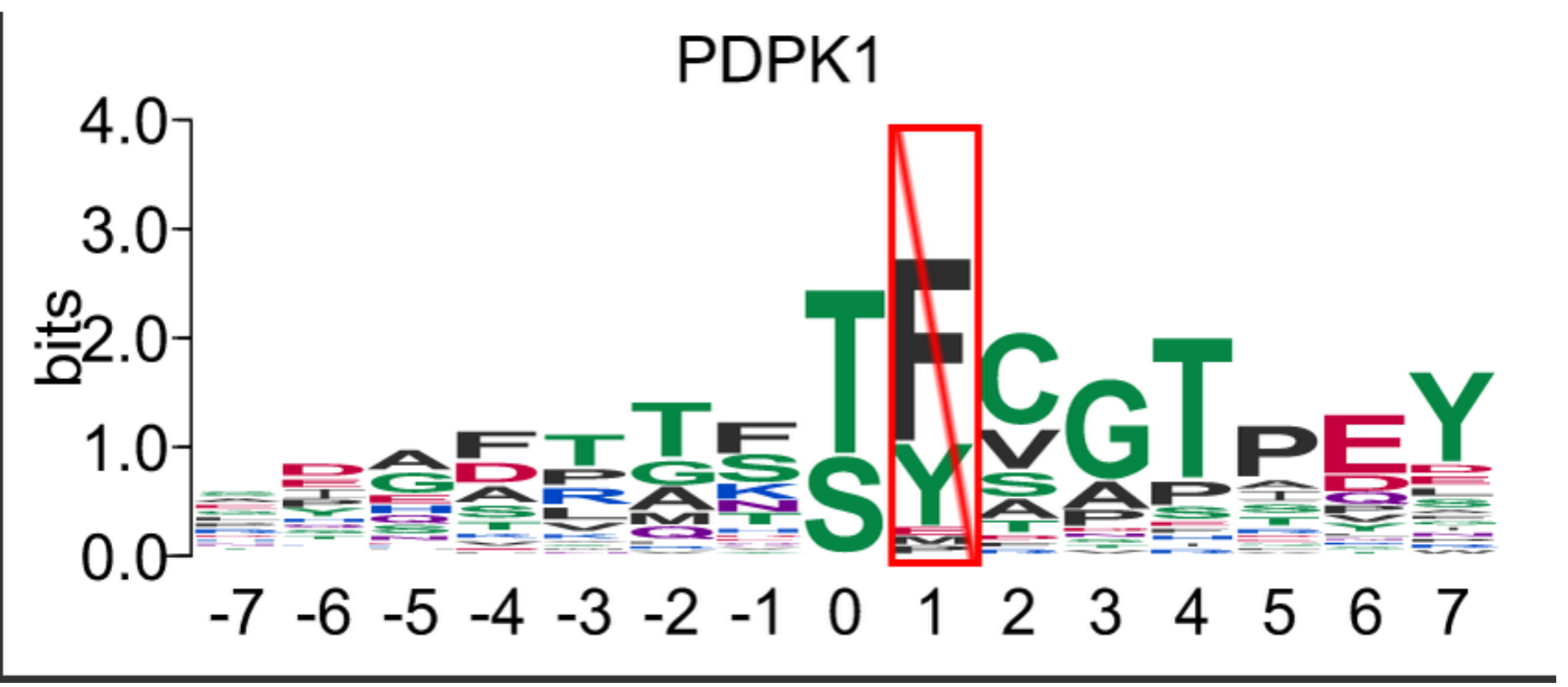

Figure 2

Zoomed needle plot shows germline mutations located in phosphorylation sites of NBN gene. The mutation rs192236678 of NBN gene is predicted to disrupt the sequence motif of the PDPK1 kinase. 


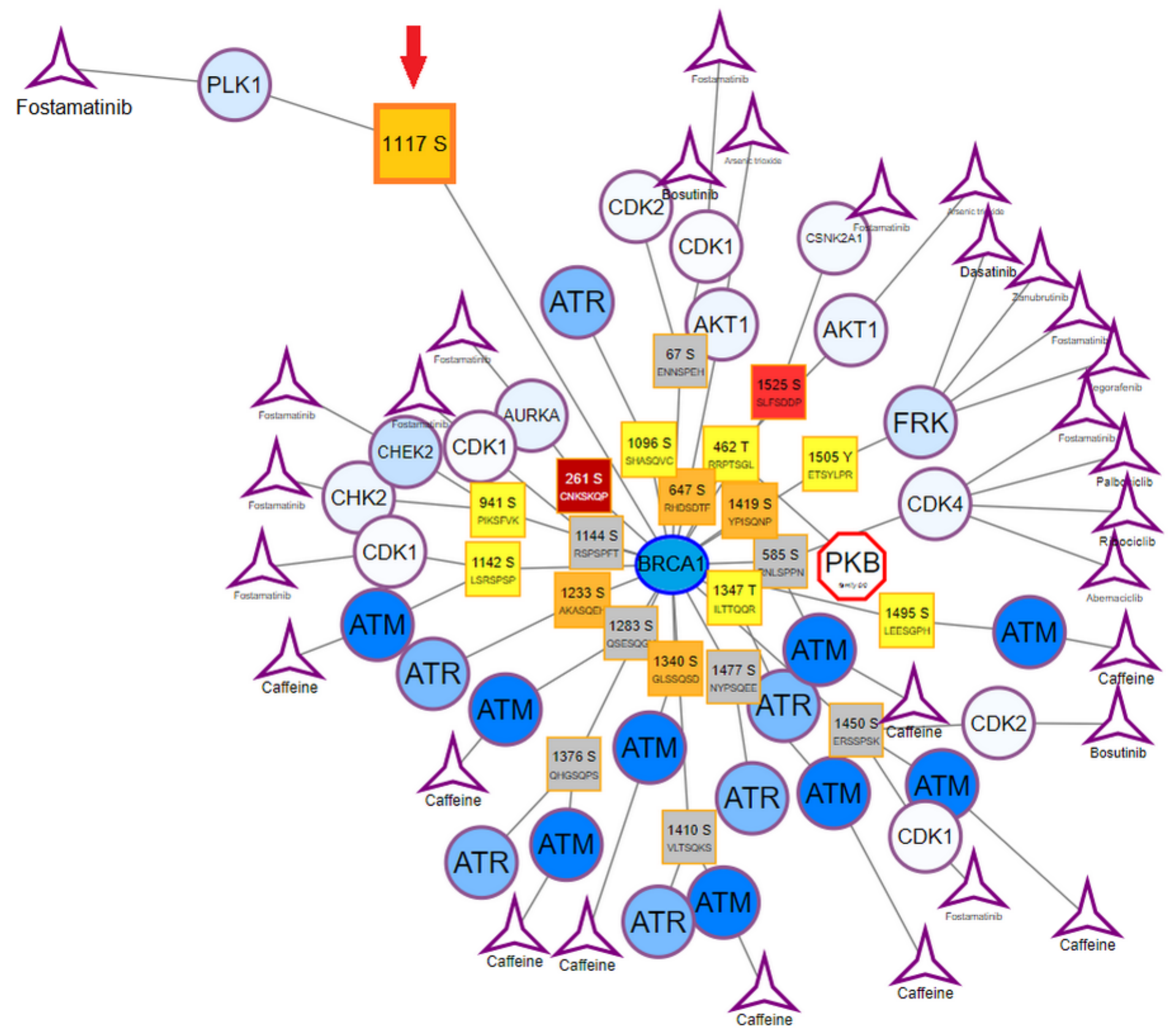

Figure 3

The computationally derived PTM interaction network of BRCA1, kinases predicted to interact with mutant BRCA1, and drugs targeting the kinases. Arrows point to the mutations 1117S. 